\title{
Discovery and identification of potential anti- melanogenic active constituents of Bletilla striata by zebrafish model and molecular docking
}

\section{Yiyuan Luo}

Zhejiang Pharmaceutical College

\section{Juan Wang}

Zhejiang Pharmaceutical College

\section{Shuo Li}

Zhejiang Pharmaceutical College

\section{Yue Wu}

Zhejiang Pharmaceutical College

\section{Zhirui Wang}

Zhejiang Pharmaceutical College

\section{Shaojun Chen}

Zhejiang Pharmaceutical College

Hongjiang Chen ( $\nabla$ chhj1228@163.com )

Zhejiang Pharmaceutical College

\section{Research Article}

Keywords: Bletilla striata, antioxidant, anti-melanogenic activity, UPLC-Q-TOF-MS/MS, zebrafish, molecular docking

Posted Date: August 31st, 2021

DOl: https://doi.org/10.21203/rs.3.rs-827709/v1

License: (c) (1) This work is licensed under a Creative Commons Attribution 4.0 International License. Read Full License

Version of Record: A version of this preprint was published at BMC Complementary Medicine and Therapies on January 7th, 2022. See the published version at https://doi.org/10.1186/s12906-021-03492-y. 


\section{Abstract \\ Background}

Bletilla striata was the main medicine of many skin whitening classic formulas in traditional Chinese medicine (TCM) and was widely used in cosmetic industry recently. However, its active ingredient was still unclear and its fibrous roots were not used effectively. The aim of the present study was to discover and identify its potential anti-melanogenic active constituents by zebrafish model and molecular docking.

\section{Methods}

The antioxidant activities were evaluated by 2,2-diphenyl-1-picrylhydrazyl (DPPH) radical scavenging activity, 2,2'-azino-bis-(3-ethylbenthiazoline-6-sulphonic acid) (ABTS) radical scavenging activity and ferric reducing antioxidant power (FRAP) assay. The anti-melanogenic activity was assessed by tyrosinase inhibitory activity in vitro and melanin inhibitory in zebrafish. The chemical profiles were performed by ultrahigh-performance liquid chromatography combined with quadrupole time-of-flight tandem mass spectrometry (UPLC-Q-TOF-MS/MS). Meanwhile, the potential anti-melanogenic active constituents were temporary identified by molecular docking.

\section{Results}

The $95 \%$ ethanol extract of $B$. striata fibrous roots (EFB) possesses the strongest DPPH, ABTS, FRAP and tyrosinase inhibition activity, with $\mathrm{IC}_{50} 5.94 \mathrm{mg} / \mathrm{L}, 11.69 \mathrm{mg} / \mathrm{L}, 6.92 \mathrm{mmol} \mathrm{FeSO}_{4} / \mathrm{g}$, and $58.92 \mathrm{mg} / \mathrm{L}$, respectively. In addition, EFB and $95 \%$ ethanol extract of $B$. striata tuber (ETB) can significantly reduce the melanin synthesis of zebrafish embryos in dose-dependent manner. 39 chemical compositions, including 24 stilbenoids were tentatively identified from EFB and ETB. Molecular docking indicated that there were 83 (including 60 stilbenoids) and 85 (including 70 stilbenoids) compounds exhibit stronger binding affinities toward tyrosinase and adenylate cyclase.

\section{Conclusion}

The present findings supported the rationale for the use of EFB and ETB as natural skin-whitening agents in pharmaceutical and cosmetic industries.

\section{Background}

Bletilla striata (Thunb.) Reichb. f. is a herbaceous perennial plant widely distributed in Asia, such as Korea, China, and Japan [1]. The dried tuber of $B$. striata, also known as Baiji, firstly recorded in Shennong's Classic of Materia Medica (Simplified Chinese: $\mathrm{Bu}$ (1), has been widely used as a traditional Chinese medicine (TCM) for thousands of years in China. Chinese pharmacopeias states that it possesses the capability of astringency upon hemostasis and analgesis, therefore, it was widely used for the treatment of hematemesis, 
hemoptysis, traumatic bleeding, ulcers, swelling and chapped skin [2, 3]. Pharmacological studies demonstrated that $B$. striata has a wide spectrum of biological activities, such as wound healing $[4,5]$, antiulcer [6, 7], hemostatic [8], anti-inflammation [9], antioxidant [10], antibacterial [11], anti-influenza viral [12], and antiaging [13]. At the same time, B. striata contains various classes of chemical compositions, including polysaccharides [14], bibenzyls, phenanthrenes, anthraquinones, flavonoids, and 2isobutylmalates [3, 15], etc.

B. striata was the main medicine of many skin whitening classic formulas in TCM [16] and it was widely used in cosmetic industry recently [17]. However, its active ingredients were still unclear and even some research results were contrary. For instance, the research results given by Chen et al indicated that $95 \%$ ethanol extract of $B$. striata possessed higher anti-tyrosinase activity than those of water extract with inhibition rate of $68.36 \%$ in vitro [18], while the result of Huang et al showed that the inhibitory activity of $B$. striata water extract on tyrosinase was stronger than that of $95 \%$ ethanol extract with inhibition rate of $62 \%$ in vitro [19]. The research results by Lu et al [20] and Linghu et al [21] demonstrated that both water and $95 \%$ ethanol extract of $B$. striata, especially chloroform fractionation, can inhibit B16 cell growth and induce its apoptosis in a concentration-dependent manner. As in vitro experiments does not reflect the real and complex metabolic conditions in living organisms, many of the samples showed significant inhibitory activity against tyrosinase and melanoma cell lines in vitro, nevertheless, exhibited weakly effective or even ineffective in vivo [22].

Meanwhile, $B$. striata fibrous roots (FB) were the by-products generated during the processing of $B$. striata tuber (TB). Modern research results indicated that the FB contains similar compounds with TB, in addition, has higher phenolic content [23], and antibacterial [24], antioxidant and anti-tyrosinase activities [23]. However, the resources of FB were not effectively used and were abandoned in the farmland, which lead to the waste of resources and environmental pollution [25].

Zebrafish (Danio rerio), a small tropical freshwater fish, is an emerging animal model for pharmacology and toxicology research in vivo, with many advantages including low cost, short life cycle, high transparency, easy to maintain, high fertility, and fewer test samples required [26, 27]. In addition, zebrafish has melanin pigments on the surface, allowing simple observation of the pigmentation process, and was widely used in the anti-melanogenic study $[26,28]$.

In the present study, we compared the antioxidant and tyrosinase inhibitory activities of crude polysaccharide and $95 \%$ ethanol extract of TB and FB in vitro, and anti-melanogenic activities in zebrafish model in vivo. Meanwhile, the potential anti-melanogenic active constituents were temporary identified by molecular docking. We discovered that $95 \%$ ethanol extract of TB (ETB) and FB (EFB) possesses the significantly antioxidant and anti-tyrosinase activities, and can reduce melanin synthesis of zebrafish embryos in dose-dependent manner. Thus, ETB and EFB can be used as natural skin-whitening agents in pharmaceutical and cosmetic industries.

\section{Methods}

\section{Chemicals and reagents}


Tyrosinase, 3-(3,4-Dihydroxyphenyl)-L-alanine (L-DOPA) and arbutin were purchased from Aladdin reagent company (Shanghai, China). 2,2-diphenyl-1-picrylhydrazyl (DPPH), 2,2'-azino-bis-(3-ethylbenthiazoline-6sulphonic acid) (ABTS), 6-hydroxy-2,5,7,8-tetramethylchroman-2-carboxylic acid (Trolox), and 2,4,6-tris(2pyridyl)-s-triazine (TPTZ) were purchased from Sigma-Aldrich (St. Louis, MO, USA). Acetonitrile and methanol were of HPLC grade and purchased from Tedia (Fairfield, OH, USA). Deionized water was prepared with the Milli-Q water system (18.2 M $\Omega$, Millipore, USA).

\section{Plant collection and extraction procedure}

B. striata were collected from Quzhou YiNianTang Agriculture and Forestry Technology Co., Ltd, Quzhou, Zhejiang, in China. Voucher specimens were deposited at Herbarium of Zhejiang Pharmaceutical College (Accession no. 190615). The whole plant was divided into tubers and fibrous roots. Subsequently, they were cut into small pieces and dried by vacuum freeze-drying, respectively.

The dried and powdered samples (TB and FB) were reflux extracted with $95 \%$ ethanol for three times (1.5 $\mathrm{h}$ for each time). The extract was filtered using Whatman filter paper (No.1) and the filtrate was concentrated to dryness under vacuum in a rotary evaporator (Hei-VAP, Heidolph, Germany) at $50{ }^{\circ} \mathrm{C}$ and vacuum freeze dryer. The ethanol extraction of TB (ETB) and FB (EFB) yield were $5.21 \%$ and $6.53 \%$, respectively. The dregs were used to extract the crude polysaccharide by dispersed in $80^{\circ} \mathrm{C}$ water for $4 \mathrm{~h}$ and precipitation with ethanol [29]. The polysaccharides yield of TB (PTB) and FB (PFB) were $14.75 \%$ and $6.45 \%$, respectively.

\section{Chemical analysis}

The chemical analysis was performed on an ultra-high-performance liquid chromatography combined with quadrupole time-of-flight tandem mass spectrometry (UPLC-Q-TOF-MS/MS). The chromatographic separation was performed using a Waters Acquity UPLC ${ }^{T M}$ system (Waters Corp., Milford, MA, US) on a Waters BEH Shield RP C18 column $(100 \times 2.1 \mathrm{~mm}, 1.7 \mu \mathrm{m})$ at $30{ }^{\circ} \mathrm{C}$. The mobile phase was consisted of $0.1 \%$ formic acid in water $(A)$ and acetonitrile $(B)$, with a linear gradient: 0-3 min, 5-16\% B; 3-8 min, 16-30\% B; 8-10 min, 30-35\% B; 10-15 min, 35-55\% B; 15-18 min, 55-80\% B; $18-19$ min, 80-5\% B; $19-20$ min, $5 \%$ B. The flow rate was $0.3 \mathrm{~mL} / \mathrm{min}$, and injection volume was $2 \mu \mathrm{L}$.

The TOF-MS/MS experiments were performed by using an AB SCEIX Triple TOF 5600 mass spectrometry (AB SCIEX, Foster City, CA, USA) equipped with an electrospray ionization (ESI). The experiment was performed using MS detection conducted in negative ionization method. The parameters were set as follows: source and desolvation temperature were $100{ }^{\circ} \mathrm{C}$ and $450{ }^{\circ} \mathrm{C}$ respectively; desolvation gas flow rate was $900 \mathrm{~L} / \mathrm{h}$; capillary voltage was $2 \mathrm{kV}$; cone voltage was $40 \mathrm{~V}$; collision energy was $22 \mathrm{eV}$; and the full scan spectra was from 100 to $2000 \mathrm{Da}$.

\section{Antioxidant assays}

\section{DPPH radical scavenging activity}

The DPPH radical scavenging activity was determined in accordance with Ali et al with slightly modifications [30]. Briefly, $50 \mu \mathrm{L}$ test sample solution was mixed with $150 \mu \mathrm{L}$ DPPH ethanol solution (0.2 
$\mathrm{mM})$ in 96-well plates and kept in the dark for $30 \mathrm{~min}$. The absorbance of the mixture at $517 \mathrm{~nm}\left(\mathrm{~A}_{1}\right)$ was assessed by microplate spectrophotometer (Thermo Fisher Scientific, America). The blank solution without test sample mixed with DPPH ethanol solution was set as the positive group $\left(A_{0}\right)$. The blank solution without DPPH mixed with test sample solution was set as the blank group $\left(A_{2}\right)$. All experiments were executed in triplicate. The DPPH radical scavenging rate was calculated using the following formula:

DPPH radical scavenging rate $(\%)=\left[A_{0}-\left(A_{1}-A_{2}\right)\right] / A_{0} \times 100 \%$

\section{ABTS radical scavenging activity}

The scavenging capacity to ABTS radical was measured using the method described by Ali et al [30]. Briefly, $7 \mathrm{mM}$ ABST aqueous solution was mixed with $2.45 \mathrm{mM}$ potassium persulfate at a ratio of $1: 1(\mathrm{~V} / \mathrm{V})$, and incubating at room temperature in the dark for $16 \mathrm{~h}$ to obtain the $\mathrm{ABST}^{+}$stock solution. The stock solution was diluted with phosphate buffered saline (PBS) to adjust the absorbance of (0.72 \pm 0.2$)$ at $734 \mathrm{~nm}$. $20 \mu \mathrm{L}$ test sample at different concentrations was mixed thoroughly with $180 \mu \mathrm{L} \mathrm{ABTS}{ }^{+}$solution. The reactive mixtures were kept in the dark for 5 min and subsequently measured the absorbance $\left(B_{1}\right)$ at $734 \mathrm{~nm}$. The absorbance of the mixtures without test sample and $\mathrm{ABST}^{+}$were set as $\mathrm{B}_{0}$ and $\mathrm{B}_{2}$, respectively. All experiments were executed in triplicate. The scavenging rate to ABTS radical was calculated according to the following formula:

ABTS radical scavenging rate $(\%)=\left[B_{0}-\left(B_{1}-B_{2}\right)\right] / B_{0} \times 100 \%$

\section{Ferric reducing antioxidant power assay (FRAP)}

The ferric iron reducing activity was determined according the procedures by Kosakowska et al [31]. 300 mM acetate buffer, $10 \mathrm{mM}$ TPTZ (2,4,6-tris(2-pyridyl)-s-triazine) and $20 \mathrm{mM} \mathrm{FeCl}_{3}$ were mixed at a ( $\left.v / v / v\right)$ ratio of 10:1:1 to prepared the working reagent. $100 \mu \mathrm{L}$ of each test sample solution was mixed with $100 \mu \mathrm{L}$ TPTZ working reagent, incubated at $37^{\circ} \mathrm{C}$ for 20 min and the absorbance was determined at $593 \mathrm{~nm}$. Meanwhile, a series of $\mathrm{FeSO}_{4}$ standard solutions in the concentration ranges of $0-1000 \mu \mathrm{g} / \mathrm{mL}$ were used to prepare the calibration curve. The ferric reducing capacity was calculated in the formation of an intense $\mathrm{Fe}^{2+}$-TPTZ blue complex. The results were expressed as $\mathrm{Fe}^{2+}$ antioxidant capacity (mmol FeSO $\mathrm{m}_{4} / \mathrm{g}^{\circ}$ extract).

\section{Tyrosinase inhibitory activity}

Tyrosinase inhibitory activities were determined by spectrophotometric method using L-DOPA as substrate [32]. Briefly, $50 \mu \mathrm{L}$ sample solution of different concentrations was mixed with $50 \mu \mathrm{L}$ tyrosinase (200 units $/ \mathrm{mL}$, dissolved in $\mathrm{pH} 6.8$ phosphate buffer) in 96-well plates and incubated for $15 \mathrm{~min}$ at $25^{\circ} \mathrm{C}$. The reaction was then initiated with the addition of $\angle$-DOPA $(50 \mu \mathrm{L})$. After incubating of $30 \mathrm{~min}$ at $25^{\circ} \mathrm{C}$, the absorbance at $490 \mathrm{~nm}\left(\mathrm{~A}_{\mathrm{a}}\right)$ was determined using a multiskan sky microplate spectrophotometer (Thermo Fisher Scientific, America). Similarly, the absorbance of the sample wells without tyrosinase $\left(A_{b}\right)$ and the 
control wells with enzyme but without sample $\left(A_{b}\right)$ were detected at the same time. The tyrosinase inhibitory activity was calculated by equation below:

Tyrosinase inhibitory rate $(\%)=\left[1-\left(A_{a}-A_{b}\right) / A_{c}\right] \times 100 \%$

\section{Melanin inhibitory in zebrafish}

Wild-type AB line zebrafish (provided by Hunter Biotechnology, Inc., Hangzhou, Zhejiang Province) were housed in fish water $(0.2 \%$ instant ocean salt in deionized water, $\mathrm{pH} 6.9-7.2$, conductivity $480-510 \mathrm{mS} / \mathrm{cm}$, and hardness $53.7-71.6 \mathrm{mg} / \mathrm{L} \mathrm{CaCO}_{3}$ ) in a $14 / 10 \mathrm{~h}$ light/dark photoperiod at a constant temperature $28 \pm 0.5$ ${ }^{\circ} \mathrm{C}$, and fed live brine shrimp twice daily. The zebrafish embryos were obtained from natural spawning and collected within $30 \mathrm{~min}$. The zebrafish assay was accredited by the Association for Assessment and Accreditation of Laboratory Animal Care (AAALAC). The present study was approved by the IACUC (Institutional Animal Care and Use Committee) at Hunter Biotechnology, Inc. and the IACUC approval number was 001458.

Embryos at the $6 \mathrm{~h}$ post fertilization (hpf) stage were treated each extract at six concentrations $(10,30,62.5$, 125,250 and $500 \mathrm{mg} / \mathrm{L}$ ) for $72 \mathrm{~h}$ to evaluating the maximum non-lethal concentration (MNLC). As a result, the MNLCs of all the extract were more than $62.50 \mathrm{mg} / \mathrm{L}$. 10 embryos were placed in 6-well and were exposed to tested samples at concentrations of 10 and $30 \mathrm{mg} / \mathrm{L}$ from $6 \mathrm{~h}$ post fertilization (hpf) to $54 \mathrm{hpf}$ (48 $\mathrm{h}$ exposure). DMSO $(0.05 \%, v / v)$ and arbutin (10 and $30 \mathrm{mg} / \mathrm{L})$ were used as the normal and positive control.

Synchronized embryos were collected and arrayed by pipette were observed under a stereomicroscope (SZX7, Olympus, Japan) equipped with a digital camera (VertA1, China). Melanin accumulation, directly correlated to the zebrafish pigmentation areas, was calculated using the GNU Image Manipulation Program (GIMP version 2.10.2) and expressed as percentage with respect to the negative control (melanin accumulation 100\%) [26, 28].

\section{Molecular docking study}

158 compounds isolated from B. striata in the literature [2], including 19 glycosides, 28 bibenzyls, 19 phenanthrenes, 18 biphenanthrenes, 23 dihydrophenanthrenes, 5 anthocyanins, 11 steroids, 8 triterpenoids, 12 phenolic acids, 5 quinones, and 10 other compounds, were used as the ligands. The 3D structures were drawn by ChemBio3D and were optimized using MM2 and Autodock Tools. The 3D crystal structure of tyrosinase (PDB ID:5M8N) and adenylate cyclase (PDB ID:5IV3) were retrieved from RCSB Protein Data Bank (www.rcsb.org/pdb/home/home.do). All water molecules and hetero atoms were removed from the crystal structures by using Chimera and MGL Tools. Finally, Autodock Vina was used to dock the receptor protein with the small molecule ligands. Parameters of the receptor protein docking site were set -36.700 , $7.034,-19.104$, and $-17.467,-22.807,2.786$, respectively, according to the original ligand mimosine and LRE1 [33].

\section{Results}




\section{Chemical composition}

The typical base peak chromatogram chromatograms of ETB and EFB were shown in Fig. 1. The PeakView ${ }^{\mathrm{TM}}$ softwares were used to identify the constituents. The molecular formula was accurately assigned within mass error of $10 \mathrm{ppm}$. The exact molecular weight and the fragment ions were used to identify the components according the literatures and the free chemical structure database, such as ChemSpider and Massbank. As a result, 39 chemical compositions, including 24 stilbenoids (bibenzyls, phenanthrenes and their derivatives), 6 glycosides, 4 phenolic acids, 3 quinones, 1 steroid, and 1 other compound were tentatively identified from EFB and ETB. At the same time, their relative semi-quantification was performed by measuring peak areas of each compound in MS mode using the extracted ion chromatograms [34]. The detailed information of the identification and their relative contents (heat map highlights, the darker the color, the higher the contentration) were summarized in Table 1.

Table 1 The compounds identified from the $95 \%$ ethanol extracts from $B$. striata tubers and fibrous roots by UPLC-Q-TOF-MS/MS, and their relative peak areas. 


\begin{tabular}{|c|c|c|c|c|c|c|c|}
\hline \multirow[t]{2}{*}{ NO. } & \multirow[t]{2}{*}{$\begin{array}{l}T_{R} \\
(\min )\end{array}$} & \multirow[t]{2}{*}{ Formula } & \multirow[t]{2}{*}{$\begin{array}{l}\text { Found } \\
\text { Mass }\end{array}$} & \multirow[t]{2}{*}{$\begin{array}{l}\text { Error } \\
(\mathrm{ppm})\end{array}$} & \multirow[t]{2}{*}{ Identification } & \multicolumn{2}{|c|}{$\begin{array}{l}\text { Relative peak } \\
\text { areas }\left(\times 10^{6}\right)\end{array}$} \\
\hline & & & & & & ETB & EFB \\
\hline 1 & 2.35 & $\mathrm{C}_{13} \mathrm{H}_{18} \mathrm{O}_{7}$ & 285.0977 & -0.8 & gastrodin & 2.17 & 1.43 \\
\hline 2 & 4.53 & $\mathrm{C}_{7} \mathrm{H}_{6} \mathrm{O}_{3}$ & 137.0248 & 3.1 & p-hydroxybenzoic acid & 0.00 & 0.77 \\
\hline 3 & 6.70 & $\mathrm{C}_{9} \mathrm{H}_{8} \mathrm{O}_{3}$ & 163.0406 & 3.2 & 3-hydroxycinnamic acid & 0.00 & 0.43 \\
\hline 4 & 7.01 & $\mathrm{C}_{34} \mathrm{H}_{32} \mathrm{O}_{8}$ & 567.2028 & 0.6 & bleochranol D & 0.00 & 2.80 \\
\hline 5 & 7.71 & $\mathrm{C}_{40} \mathrm{H}_{56} \mathrm{O}_{22}$ & 887.3179 & -1.3 & dactylorhin A & 3.93 & 3.06 \\
\hline 6 & 8.13 & $\mathrm{C}_{21} \mathrm{H}_{22} \mathrm{O}_{8}$ & 401.1228 & -3.6 & $\begin{array}{l}\text { 2,7-dihydroxy-4- } \\
\text { methoxyphenanthrene-2-0- } \\
\text { glucoside }\end{array}$ & 0.00 & 0.00 \\
\hline 7 & 8.21 & $\mathrm{C}_{27} \mathrm{H}_{32} \mathrm{O}_{13}$ & 563.1747 & -4.1 & $\begin{array}{l}\text { 2,7-dihydroxy-4- } \\
\text { methoxyphenanthrene-2,7- } \\
\text { O-diglucoside }\end{array}$ & 0.00 & 1.18 \\
\hline 8 & 9.62 & $\mathrm{C}_{34} \mathrm{H}_{46} \mathrm{O}_{17}$ & 725.2635 & -3.8 & militarine & 30.48 & 38.39 \\
\hline 9 & 9.76 & $\mathrm{C}_{20} \mathrm{H}_{22} \mathrm{O}_{6}$ & 357.1332 & -3.3 & pinoresinol & 0.00 & 0.00 \\
\hline 10 & 10.31 & $\mathrm{C}_{21} \mathrm{H}_{26} \mathrm{O}_{8}$ & 405.1537 & -4.5 & $\begin{array}{l}\text { 3'-hydroxy-5- } \\
\text { methoxybibenzyl-3-0- } \beta \text {-D- } \\
\text { glucopyranoside }\end{array}$ & 0.72 & 1.56 \\
\hline 11 & 11.08 & $\mathrm{C}_{16} \mathrm{H}_{12} \mathrm{O}_{5}$ & 283.0601 & -3.8 & $\begin{array}{l}\text { 1,8-dihydroxy-3-methoxy-6- } \\
\text { methylanthracene-9,10- } \\
\text { dione }\end{array}$ & 0.00 & 1.53 \\
\hline 12 & 12.15 & $\mathrm{C}_{15} \mathrm{H}_{13} \mathrm{O}_{4}$ & 256.0734 & -3.0 & $\begin{array}{l}\text { 7-hydroxy-2- } \\
\text { methoxyphenanthrene-3,4- } \\
\text { dione }\end{array}$ & 0.00 & 0.00 \\
\hline 13 & 12.42 & $\mathrm{C}_{15} \mathrm{H}_{12} \mathrm{O}_{3}$ & 239.0714 & 0.3 & $\begin{array}{l}\text { 4-methoxyphenanthrene-2,7- } \\
\text { diol }\end{array}$ & 0.00 & 1.92 \\
\hline 14 & 12.99 & $\mathrm{C}_{16} \mathrm{H}_{14} \mathrm{O}_{4}$ & 269.0820 & 0.2 & $\begin{array}{l}\text { 2,7-dihydroxy-3,4- } \\
\text { dimethoxyphenanthrene }\end{array}$ & 0.00 & 6.01 \\
\hline 15 & 13.54 & $\mathrm{C}_{51} \mathrm{H}_{64} \mathrm{O}_{24}$ & 1059.3674 & -3.8 & gymnoside $X$ & 1.07 & 0.89 \\
\hline 16 & 13.64 & $\mathrm{C}_{28} \mathrm{H}_{26} \mathrm{O}_{5}$ & 441.1691 & -3.7 & shanciguol & 0.00 & 1.51 \\
\hline 17 & 13.80 & $\mathrm{C}_{16} \mathrm{H}_{18} \mathrm{O}_{4}$ & 273.1126 & -2.2 & $\begin{array}{l}\text { 3,3'-dihydroxy-5,4'- } \\
\text { dimethoxybibenzyl }\end{array}$ & 0.00 & 0.00 \\
\hline 18 & 13.88 & $\mathrm{C}_{15} \mathrm{H}_{16} \mathrm{O}_{3}$ & 243.1026 & -0.4 & $\begin{array}{l}\text { 3,3'-dihydroxy-5- } \\
\text { methoxybibenzyl }\end{array}$ & 0.00 & 1.80 \\
\hline 19 & 14.07 & $\mathrm{C}_{22} \mathrm{H}_{20} \mathrm{O}_{4}$ & 347.1278 & -3.2 & $\begin{array}{l}\text { 4,7-dihydroxy-1-( } p \text { - } \\
\text { hydroxybenzyl)-2-methoxy- }\end{array}$ & 0.32 & 0.00 \\
\hline
\end{tabular}


9,10-dihydrophenanthrene

$\begin{array}{llllllll}20 & 14.26 & \mathrm{C}_{29} \mathrm{H}_{24} \mathrm{O}_{5} & 451.1507 & -9.8 & \begin{array}{l}\text { 1,8-bis(p-hydroxybenzyl)-4- } \\ \text { methoxyphenanthrene-2,7- } \\ \text { diol }\end{array} & 0.00 & 8.73\end{array}$

$21 \quad 14.31 \quad \mathrm{C}_{22} \mathrm{H}_{18} \mathrm{O}_{4} \quad 345.1124 \quad-2.4 \quad 1$-(p-hydroxybenzyl)-4-

methoxyphenanthrene-2,7-

$0.25 \quad 0.00$

diol

$\begin{array}{llllllll}22 & 14.50 & \mathrm{C}_{25} \mathrm{H}_{24} \mathrm{O}_{6} & 419.1480 & -4.8 & \text { bleochranol B } & 0.21 & 1.89 \\ 23 & 14.67 & \mathrm{C}_{23} \mathrm{H}_{20} \mathrm{O}_{5} & 375.1225 & -3.6 & \text { bleformin B } & 0.00 & 5.08 \\ 24 & 14.71 & \mathrm{C}_{30} \mathrm{H}_{26} \mathrm{O}_{6} & 481.1631 & -5.3 & \text { blestrin A } & 0.79 & 5.08 \\ 25 & 14.89 & \mathrm{C}_{22} \mathrm{H}_{22} \mathrm{O}_{4} & 349.1434 & -3.1 & \begin{array}{l}\text { 3,3'-dihydroxy-4-( }(p- \\ \text { hydroxybenzyl)-5- } \\ \text { methoxybibenzyl }\end{array} & 0.00 & 0.00\end{array}$

$\begin{array}{cccccccc}26 & 14.94 & \mathrm{C}_{30} \mathrm{H}_{24} \mathrm{O}_{6} & 479.1478 & -4.6 & \text { blestrin D } & 0.46 & 1.91 \\ 27 & 15.53 & \mathrm{C}_{32} \mathrm{H}_{26} \mathrm{O}_{8} & 537.1529 & -4.9 & \begin{array}{l}4,8,4^{\prime}, 8^{\prime} \text {-tetramethoxy-[1,1'- } \\ \text { biphenanthrene]-2,7,2, } \\ \text { tetrol }\end{array} & 0.01 & 9.15\end{array}$

$\begin{array}{cccccccc}28 & 15.74 & \mathrm{C}_{37} \mathrm{H}_{32} \mathrm{O}_{7} & 587.2047 & -4.9 & \text { bleformin D } & 0.00 & 9.63 \\ 29 & 16.08 & \mathrm{C}_{15} \mathrm{H}_{14} \mathrm{O}_{3} & 241.0869 & -0.7 & \begin{array}{l}\text { 2,4-dimethoxyphenanthrene- } \\ \text { 7-ol }\end{array} & 0.13 & 1.48\end{array}$

\begin{tabular}{ccccclcc}
30 & 16.49 & $\mathrm{C}_{27} \mathrm{H}_{26} \mathrm{O}_{7}$ & 461.1584 & -4.7 & pleionesin C & 0.04 & 0.36 \\
31 & 16.61 & $\mathrm{C}_{16} \mathrm{H}_{14} \mathrm{O}_{3}$ & 253.0862 & -3.1 & $\begin{array}{l}\text { 2-hydroxy-4,7- } \\
\text { dimethoxyphenanthrene }\end{array}$ & 0.01 & 1.42 \\
32 & 16.89 & $\mathrm{C}_{18} \mathrm{H}_{18} \mathrm{O}_{4}$ & 297.1126 & -2.1 & $\begin{array}{l}\text { 2,3,4,7- } \\
\text { tetramethoxyphenanthrene }\end{array}$ & 0.01 & 2.28 \\
33 & 16.94 & $\mathrm{C}_{29} \mathrm{H}_{26} \mathrm{O}_{5}$ & 453.1671 & -8.2 & $\begin{array}{l}\text { 2,7-dihydroxy-1,6-bis }(p- \\
\text { hydroxybenzyl)-4-methoxy- } \\
\text { 9,10-dihydrophenanthrene }\end{array}$ & 0.10 & 0.64 \\
\hline
\end{tabular}

\begin{tabular}{|c|c|c|c|c|c|c|c|}
\hline 34 & 17.46 & $\mathrm{C}_{23} \mathrm{H}_{24} \mathrm{O}_{4}$ & 363.1585 & -4.7 & bulbocol & 0.15 & 3.85 \\
\hline 35 & 17.67 & $\mathrm{C}_{22} \mathrm{H}_{22} \mathrm{O}_{3}$ & 333.1486 & -3.2 & $\begin{array}{l}\text { 5-hydroxy-2-(p- } \\
\text { hydroxybenzyl)-3- } \\
\text { methoxybibenzyl }\end{array}$ & 0.60 & 3.34 \\
\hline 36 & 18.27 & $\mathrm{C}_{27} \mathrm{H}_{35} \mathrm{O}_{9}$ & 502.2211 & 0.5 & $\begin{array}{l}(20 S, 22 R)-1 \beta, 2 \beta, 3 \beta, 4 \beta, 5 \beta, 7 \alpha- \\
\text { hexahydroxyspirost-25(27)- } \\
\text { en-6-one }\end{array}$ & 9.14 & 1.06 \\
\hline 37 & 18.30 & $\mathrm{C}_{18} \mathrm{H}_{30} \mathrm{O}_{3}$ & 293.2117 & -1.7 & striatolide & 0.00 & 2.49 \\
\hline 38 & 18.78 & $\mathrm{C}_{16} \mathrm{H}_{32} \mathrm{O}_{2}$ & 255.2327 & -1.0 & palmitic acid & 0.00 & 0.95 \\
\hline 39 & 18.87 & & 522.1329 & $\begin{array}{r}1.7 \\
\mathrm{Pac}\end{array}$ & $3^{\prime}, 7^{\prime}, 7$-trihydroxy-2,2',4'- & 7.20 & 0.76 \\
\hline
\end{tabular}



$\mathrm{C}_{31} \mathrm{H}_{23} \mathrm{O}_{8}$
trimethoxy-[1, $8^{-}-$
biphenanthrene]-3,4-dione

Total

57.79

123.37

\section{Antioxidant capacity}

It is well known that Ultraviolet A (UVA)-irradiation can induce reactive oxygen species (ROS) production and mediate excessive melanogenesis in skin cells. Natural polyphenols was the inhibitors of ROS generation and could be responsible for the anti-melanogenic activity of plant extracts $[35,36]$. Thus, in the present study, the antioxidant capacity was assessed through 2,2-diphenyl-1-picrylhydrazyl (DPPH) radical scavenging activity, 2,2'-azino-bis-(3-ethylbenthiazoline-6-sulphonic acid) (ABTS) radical scavenging activity and ferric reducing antioxidant power (FRAP) assay.

The results (Table 2) showed that the EFB $\left(\mathrm{IC}_{50}=5.94 \mathrm{mg} / \mathrm{L}\right)$ possesses the strongest $\mathrm{DPPH}$ radical scavenging activity in vitro compared to the PTB $\left(\mathrm{IC}_{50}=548.24 \mathrm{mg} / \mathrm{L}\right), \mathrm{PFB}\left(\mathrm{IC}_{50}=285.81 \mathrm{mg} / \mathrm{L}\right)$, and ETB $\left(\mathrm{IC}_{50}=65.25 \mathrm{mg} / \mathrm{L}\right)$. A similar trend was observed in ABTS and FRAP assay. The $95 \%$ ethanolic extracts of TB and PB had stronger antioxidation activity in vitro than their crude polysaccharides. In addition, EFB exhibit stronger antioxidation activity than ETB, which was consistent with the previous research results [23].

Table 2 The results of antioxidant activity analyses in vitro (DPPH, ABTS and FRAP).

\begin{tabular}{|c|c|c|c|}
\hline \multirow[t]{2}{*}{ Sample } & \multicolumn{2}{|l|}{$\mathrm{IC}_{50}$ values $(\mathrm{mg} / \mathrm{L})$} & \multirow{2}{*}{$\begin{array}{l}\text { FRAP } \\
\mathrm{mmol} \mathrm{FeSO}_{4} / \mathrm{g}\end{array}$} \\
\hline & DPPH scavenging & ABTS scavenging & \\
\hline PTB & $548.24 \pm 8.93^{a}$ & $626.49 \pm 9.75^{a}$ & $0.11 \pm 0.01^{\mathrm{a}}$ \\
\hline PFB & $285.81 \pm 5.31^{\mathrm{b}}$ & $348.62 \pm 6.30^{\mathrm{b}}$ & $0.42 \pm 0.03^{b}$ \\
\hline ETB & $65.25 \pm 1.85^{c}$ & $78.40 \pm 2.51^{c}$ & $2.45 \pm 0.05^{c}$ \\
\hline EFB & $5.94 \pm 0.46^{d}$ & $11.69 \pm 0.64^{d}$ & $6.92 \pm 0.10^{d}$ \\
\hline Trolox & $3.52 \pm 0.27^{e}$ & $3.68 \pm 0.31^{\mathrm{e}}$ & - \\
\hline
\end{tabular}

Means marked in columns with different letters differ at $p<0.05$.

\section{Tyrosinase inhibitory activity}

Tyrosinase was the key rate-limiting enzyme in melanin biosynthesis pathway and was widely used to identify the potential of natural products with anti-melanogenesis effect [37]. The results (Fig. 2) showed that ETB and EPB had stronger tyrosinase inhibitory activity in vitro than PTB and PPB, which was consistent with previous research results [23]. Meanwhile, the $\mathrm{IC}_{50}$ was calculated using an $\mathrm{IC}_{50}$ Calculator (https://www.aatbio.com/tools/ic50-calculator). EFB exhibit stronger tyrosinase inhibition activity in a dose 
dependent manner with $\mathrm{IC}_{50}=58.92 \mathrm{mg} / \mathrm{L}$ than $\mathrm{ETB}\left(\mathrm{IC}_{50}=75.44 \mathrm{mg} / \mathrm{L}\right)$ and the positive compound arbutin $\left(\mathrm{IC} \mathrm{C}_{50}=66.02 \mathrm{mg} / \mathrm{L}\right)$.

\section{Melanin inhibitory in zebrafish}

Zebrafish are recognized as a highly advantageous vertebrate model system to evaluate antimelanogenesis activity, as it possesses similar organ systems and gene sequences to human beings [26]. Therefore, zebrafish was used for the anti-melanogenesis activity. As shown in Fig. 3, a large number of melanin (black spots) deposited in the zebrafish embryo in the control and 0.05\% DMSO group. The microscopy images showed there was no significant difference in total melanin content between two groups ( $p>0.05$ ), indicating that the vehicle $0.05 \%$ DMSO didn't affect the melanin production in zebrafish embryos. However, after exposure to the tested samples and arbutin for $48 \mathrm{~h}$, zebrafish embryos exhibited varying degrees of melanin deposition (Fig. 2B, 3), excepting PFB $10 \mathrm{mg} / \mathrm{L}$ group. It is noticeable that the relative melanin contents in ETB $10 \mathrm{mg} / \mathrm{L}(78.38 \%)$ and $30 \mathrm{mg} / \mathrm{L}(64.72 \%)$ groups were significant lower than that in PTB $10 \mathrm{mg} / \mathrm{L}(93.06 \%)$ and $30 \mathrm{mg} / \mathrm{L}(82.02 \%)$ groups $(p<0.01)$. It demonstrated that the antimelanogenesis activity of ETB was superior to that of PTB, which was consistent with the tyrosinase inhibitory activity. Whereafter, at the same time, anti-melanogenesis activity of ETB $(81.65 \%, 75.61 \%)$ and EFB $(78.38 \%, 64.72 \%)$ were stronger than that of arbutin $(93.57 \%, 81.48 \%)$ at same dose of $10 \mathrm{mg} / \mathrm{L}$ and 30 $\mathrm{mg} / \mathrm{L}(p<0.01$ or 0.05$)$.

\section{Molecular docking}

Tyrosinase is the rate-limiting enzyme in melanin biosynthesis: hydroxylation of tyrosine to 3,4dihydroxyphenylalanine (DOPA), and oxidation of DOPA to dopaquinone. Therefore, tyrosinase has been considered a critical target for the development of melanogenesis inhibitors [38]. Additionally, adenylate cyclase is key enzyme of cAMP-induced melanogenesis. The binding of melanotropin alpha polypeptide (a$\mathrm{MSH}$ ) to MC1R receptors induced the activation of adenylate cyclase, increase in the cAMP level, upregulated expression of tyrosinase gene, and subsequently increase the melanin synthesis [39]. Therefore, we performed a molecular docking study of the 158 compounds isolated from B. striata previously [2], with tyrosinase and adenylate cyclase. The binding energies of the studied ligands with tyrosinase and adenylate cyclase were summaried in Table S1. There were 83 (including 60 stilbenoids) and 85 (including 70 stilbenoids) compounds exhibit stronger binding affinities toward tyrosinase and adenylate cyclase, comparing to the binding affinity of the original ligand mimosine $(-6.4 \mathrm{kcal} / \mathrm{mol})$ and LRE1 $(-8.5 \mathrm{kcal} / \mathrm{mol})$. 1,8-bis(p-hydroxybenzyl)-4-methoxyphenanthrene-2,7-diol (56), blestrin D (75), and 2,7-dihydroxy-1,6-bis(phydroxybenzyl)-4-methoxy-9,10-dihydrophenanthrene (93) were the top three ligands toward tyrosinase, with binding energy $-10.2,10.0$, and $9.7 \mathrm{kcal} / \mathrm{mol}$, respectivey. While blestrin $\mathrm{D}(\mathbf{7 5})$, blestrin $B(73)$, and 3,3'dihydroxy-5-methoxy-2,5',6-tris(p-hydroxybenzyl) bibenzyl (42) were the top three ligands toward adenylate cyclase, with binding energy $-12.1,-11.9$, and $-11.6 \mathrm{kcal} / \mathrm{mol}$, respectivey. Their theoretical binding affinities and ligand-amino acid interactions were summaried in Table 3.

Table 3 Summary of binding affinities and ligand-amino acid interactions. 


\begin{tabular}{|c|c|c|c|c|}
\hline Protease & Ligand & $\begin{array}{l}\text { Binding } \\
\text { Energy } \\
(\mathrm{kcal} / \mathrm{mol})\end{array}$ & $\begin{array}{l}\text { No. } \\
\text { of } \\
\text { H- } \\
\text { Bond }\end{array}$ & Ligand-amino acid interations \\
\hline \multirow[t]{3}{*}{ Tyrosinase } & $\begin{array}{l}\text { 1,8-bis(p- } \\
\text { hydroxybenzyl)-4- } \\
\text { methoxyphenanthrene- } \\
\text { 2,7-diol }\end{array}$ & -10.2 & 0 & $\begin{array}{l}\text { Lys233, Leu229, Arg114, Glu451, } \\
\text { Arg230, Pro115, Gly107, Pro445, } \\
\text { Met452, Tyr226, Ser106, Asn459 }\end{array}$ \\
\hline & blestrin D & -10.0 & 2 & $\begin{array}{l}\text { Pro446, Arg114, Pro445, Ser106, } \\
\text { Gly107, Cys113, Lys233, Arg230, } \\
\text { Pro115, Tyr226, Leu229, Met452, } \\
\text { Glu451 }\end{array}$ \\
\hline & $\begin{array}{l}\text { 2,7-dihydroxy-1,6-bis(p- } \\
\text { hydroxybenzyl)-4- } \\
\text { methoxy- } \\
\text { 9,10dihydrophenanthrene }\end{array}$ & -9.7 & 6 & $\begin{array}{l}\text { Glu232, Leu229, lle128, Pro115, } \\
\text { Tyr226, Glu451, Val447, Gly107, } \\
\text { Thr112, Ser106, Cys113, Lys223, } \\
\text { GIn236 }\end{array}$ \\
\hline \multirow[t]{3}{*}{$\begin{array}{l}\text { Adenylate } \\
\text { cyclase }\end{array}$} & blestrin D & -12.1 & 1 & $\begin{array}{l}\text { Val167, Leu166, Lys95, Phe45, Ala97, } \\
\text { Asn412, Arg416, Ala415, Val172, } \\
\text { Phe336, Phe338, Arg176, Leu102, } \\
\text { Met337 }\end{array}$ \\
\hline & blestrin B & -11.9 & 3 & $\begin{array}{l}\text { MeT419, Phe338, Phe45, Lys95, } \\
\text { Met337, Leu166, Phe165, Phe336, } \\
\text { Leu102, Val167, Ala97, Phe296, } \\
\text { Ala415, Arg416 }\end{array}$ \\
\hline & 3,3',5-trimethoxybibenzyl & -11.6 & 2 & $\begin{array}{l}\text { Asp47, Ala100, Leu345, Ala97, } \\
\text { Phe336, Phe296, Met419, Ala415, } \\
\text { Met418, Lys95, Leu166, Val335, } \\
\text { Phe165, Leu102, Phe45, Phe338, } \\
\text { Asn180, Arg176, Gln179 }\end{array}$ \\
\hline
\end{tabular}

It was worth noting that blestrin $D(75)$, a biphenanthrenes compound, insided binding pocket of tyrosinase and adenylate cyclase (Fig. 4) and exhibited significant binding affinities toward both tyrosinase and adenylate cyclase. The Van der Walls interactions contributes to overall energy interaction value, meanwhile hydroxyl group produces hydrogen bonds with amino acid residues Glu 451, Arg114 of tyrosinase, and Val 167 of adenylate cyclase, respectivey (Fig. 5). Compound 93 also exhibited significant binding affinities toward tyrosinase through formation of 6 hydrogen bonds with amino acid residues Glu232, Glu451, Ser106, Cys113, Lys223, and GIn236.

\section{Discussion}

It was worth noting that the types and contents of the chemical components in EFB were more than that in ETB. The peak areas of all the identified compounds in EFB were approximately two-fold of that in ETB. Militarine was the most abundant compounds in both EFB and ETB, which possessed significant antioxidant, anti-inflammatory and neuroprotection activities, and was chosen as the chemical markers for the quality control of B. striata in Chinese Pharmacopoeia 2020 edition [40]. The relative peak area of 
militarine in EFB $\left(38.39 \times 10^{6}\right)$ was slightly higher than that in ETB $\left(30.48 \times 10^{6}\right)$. Gastrodin is a well known compound in many Chinese herbal medicines, such as Gastrodia elata, which exhibit significant tyrosinase inhibitory and radical scavenging effects [28]. The relative peak area of gastrodin in EFB $\left(1.43 \times 10^{6}\right)$ was slightly lower than that in ETB $\left(2.17 \times 10^{6}\right)$.

The 95\% ethanolic extracts of TB and PB had stronger antioxidation activity in vitro than their crude polysaccharides. In addition, EFB exhibit stronger antioxidation activity than ETB, which was consistent with the previous research results [23]. This phenomenon may be attributed to that the EFB contains higher level of antioxidant compounds, such as militarine and stilbenoids (natural plant polyphenols). For example, the

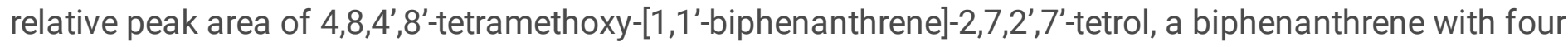
phenolic hydroxyl groups, was $9.15 \times 10^{6}$ in FB, while it was $0.01 \times 10^{6}$ in TB.

In the present study, PPB and PTB showed slight tyrosinase inhibition activity in a dose dependent manner. However, it demonstrated that no activity was detected in the aqueous extract of PB (contains PPB) [23]. This phenomenon may be due to the different sample preparation. The aqueous extract of PB was used to the evaluate tyrosinase inhibitory activity in Jiang's experiment [23], while in the present study, aqueous extract was precipitation with ethanol to obtain the crude polysaccharide.

Recently, the zebrafish model widely used in evaluation of anti-melanogenesis effect in vivo[41, 42]. Arbutin, a hydroquinone glucoside compound existing in various plants, which has been commercially used in the cosmetic industry, was set as positive control. The anti-melanogenesis activities of ETB and EFB were stronger than that of arbutin, indicating that ETB and EFB can be applied as skin-lightening agents in cosmetic industry.

The relative peak area of blestrin D in EFB $\left(1.91 \times 10^{6}\right)$, is approximately four times of that in ETB $\left(0.46 \times 10^{6}\right)$. The relative peak area of compound $56\left(8.73 \times 10^{6}\right)$ and $\mathbf{9 3}\left(0.64 \times 10^{6}\right)$ in EFB is also significant higher than that in ETB $\left(0.00 \times 10^{6}\right.$ and $\left.0.10 \times 10^{6}\right)$. This may be one of the reasons why EFB exhibits stronger antimelanogenic effects than ETB. It is interesting to note that top three ligands toward tyrosinase and adenylate cyclase all belong to stilbenoids (bibenzyls, phenanthrenes and its derivative). Stilbenoids were the natural plant polyphenols, which has attracted great interest in the last years because of their remarkable bioactivities such as anti-inflammatory, antimicrobial and antioxidant activity [43]. Resveratrol is the most common stilbenoid. The previous research indicated that resveratrol and its derivatives can significantly inhibit the catalytic activity, gene expression, and posttranslational modifications of tyrosinase. Thus, they showed potentially useful as skin lightening and antiaging agents in cosmetics [35, 44].

\section{Conclusions}

In this study, the antioxidant and anti-melanogenic activity of the crude polysaccharide from the $B$. striata tuber (PTB) and fibrous roots (FPB), and $95 \%$ ethanol extract of $B$. striata tuber (ETB) and fibrous roots (EFB) were systematically investigated. The results show that EFB possesses the strongest DPPH, ABTS radical scavenging activity and ferric iron reducing activity. In addition, ETB and EFB can significantly reduce tyrosinase activity in vitro and melanin synthesis of zebrafish embryos in dose-dependent manner.

Page $13 / 22$ 
Molecular docking indicated that there were a large number of compounds, mostly belongs to stilbenoids, exhibit stronger binding affinities toward tyrosinase and adenylate cyclase, comparing to the binding affinity of the original ligand. The present findings supported the rationale for the use of ETB and EFB as natural skin-whitening agents in pharmaceutical and cosmetic industries.

\section{Abbreviations}

TCM: Traditional Chinese medicine; TB: Bletilla striata tuber; FB: Bletilla striata fibrous roots; ETB: $95 \%$ ethanol extract of Bletilla striata tuber; EFB: $95 \%$ ethanol extract of Bletilla striata fibrous roots; PTB: Crude polysaccharide of Bletilla striata tuber; PFB: Crude polysaccharide of Bletilla striata fibrous roots; DPPH: 2,2Diphenyl-1-picrylhydrazyl; TPTZ: 2,4,6-Tris(2-pyridyl)-s-triazine; FRAP: Ferric reducing antioxidant power assay; ABTS: 2,2'-Azino-bis-(3-ethylbenthiazoline-6-sulphonic acid; Trolox: 6-Hydroxy-2,5,7,8tetramethylchroman-2-carboxylic acid; L-DOPA: 3-(3,4-Dihydroxyphenyl)-L-alanine; UPLC-Q-TOF-MS/MS: Ultra-high-performance liquid chromatography combined with quadrupole time-of-flight tandem mass spectrometry; MNLC: Maximum non-lethal concentration; ROS: Reactive oxygen species.

\section{Declarations}

\section{Acknowledgements}

Hunter Biotechnology, Inc., Hangzhou, Zhejiang Province is highly acknowledged for performing the antimelanogenic activity evaluation in zebrafish.

\section{Data Availability}

The datasets used and/or analysed during the current study are available from the corresponding author on reasonable request.

\section{Authors' Contribution}

YYL, HJC designed the experiments, analyzed the data and drafted the manuscript; YYL performed the UPLC-Q-TOF-MS/MS analysis; SL, YW, ZRW performed the antioxidant analysis; JW, SJC performed the molecular docking analysis; All authors reviewed and approved the manuscript.

\section{Funding}

This work was supported by the Programs for Science and Technology Development of Quzhou (No.2018k14), Zhejiang Traditional Chinese Medicine Technology Project (No.2020ZQ049) and Zhejiang University Students' Science and Technology Innovation Activity Plan (No.2021R460004).

\section{Data Availability}

Te data used to support the findings of this study are available from the corresponding author upon request.

\section{Ethics approval and consent to participate}


This work was approved by the IACUC (Institutional Animal Care and Use Committee) at Hunter Biotechnology, Inc. and the IACUC approval number was 001458.

\section{Consent for publication}

Not applicable.

\section{Competing interests}

The authors declare that they have no competing interests.

\section{Author details}

${ }^{1}$ College of Chinese Medicine, Zhejiang Pharmaceutical College, Ningbo 315100, China

${ }^{2}$ College of Pharmacy, Nanjing University of Chinese Medicine, Nanjing 210046, China

\section{References}

1. Zhang M, Shao Q, Xu E, Wang Z, Wang Z, Yin L: Bletilla striata: a review of seedling propagation and cultivation modes. Physiol Mol Biol Plants. 2019; 25(3):601-9.

2. Xu D, Pan Y, Chen J: Chemical constituents, pharmacologic properties, and clinical applications of Bletilla striata. Front Pharmacol. 2019; 10:1168.

3. He X, Wang X, Fang J, Zhao Z, Huang L, Guo H, Zheng X: Bletilla striata: Medicinal uses, phytochemistry and pharmacological activities. J Ethnopharmacol. 2017; 195:20-38.

4. Huang Y, Shi F, Wang L, Yang Y, Khan BM, Cheong KL, Liu Y: Preparation and evaluation of Bletilla striata polysaccharide/carboxymethyl chitosan/Carbomer 940 hydrogel for wound healing. Int J Biol Macromol. 2019; 132:729-37.

5. Zhang C, He Y, Chen Z, Shi J, Qu Y, Zhang J: Effect of polysaccharides from Bletilla striata on the healing of dermal wounds in mice. Evid Based Complement Alternat Med. 2019; 2019:9212314.

6. Morita H, Koyama K, Sugimoto Y, Kobayashi J: Antimitotic activity and reversal of breast cancer resistance protein-mediated drug resistance by stilbenoids from Bletilla striata. Bioorg Med Chem Lett. 2005; 15(4):1051-4.

7. Zhang C, Gao F, Gan S, He Y, Chen Z, Liu X, Fu C, Qu Y, Zhang J: Chemical characterization and gastroprotective effect of an isolated polysaccharide fraction from Bletilla striata against ethanolinduced acute gastric ulcer. Food Chem Toxicol. 2019; 131:110539.

8. Wang W, Meng H: Cytotoxic, anti-inflammatory and hemostatic spirostane-steroidal saponins from the ethanol extract of the roots of Bletilla striata. Fitoterapia. 2015; 101:12-8.

9. Jiang F, Li M, Wang H, Ding B, Zhang C, Ding Z, Yu X, Lv G: Coelonin, an anti-inflammation active component of Bletilla striata and its potential mechanism. Int J Mol Sci. 2019; 20(18): 4422.

10. Song Y, Zeng R, Hu L, Maffucci KG, Ren X, Qu Y: In vivo wound healing and in vitro antioxidant activities of Bletilla striata phenolic extracts. Biomed Pharmacother. 2017; 93:451-61. 
11. Guo JJ, Dai BL, Chen NP, Jin LX, Jiang FS, Ding ZS, Qian CD: The anti-Staphylococcus aureus activity of the phenanthrene fraction from fibrous roots of Bletilla striata. BMC Complement Altern Med. 2016; 16(1):491.

12. Shi Y, Zhang B, Lu Y, Qian C, Feng Y, Fang L, Ding Z, Cheng D: Antiviral activity of phenanthrenes from the medicinal plant Bletilla striata against influenza A virus. BMC Complement Altern Med. 2017; $17(1): 273$.

13. Zhang Y, Lv T, Li M, Xue T, Liu H, Zhang W, Ding X, Zhuang Z: Anti-aging effect of polysaccharide from Bletilla striata on nematode Caenorhabditis elegans. Pharmacogn Mag. 2015; 11(43):449-54.

14. Chen Z, Zhao Y, Zhang M, Yang X, Yue P, Tang D, Wei X: Structural characterization and antioxidant activity of a new polysaccharide from Bletilla striata fibrous roots. Carbohydr Polym. 2020; 227:115362.

15. Guan HY, Yan Y, Wang YL, Wang AM, Liu JH, He X, Li YJ, Huang Y, Liao SG: Isolation and characterization of two new 2-isobutylmalates from Bletilla striata. Chin J Nat Med. 2016; 14(11):8715.

16. Jiang J, Chen HX, Tang XL, Zhou YF: Consideration on development of Bletillae striata based on whitening theory in traditional Chinese medicine. Chin Tradit Herbal Drugs. 2017; 48(11):2313-20.

17. Zhang M, Han TT, Hu CF, Bai Y, Fan ZP, Hong L: Industrialization condition and sustainable development strategies of Bletillae Rhizoma. Chin Tradit Herbal Drugs. 2019; 50(20):5103-8.

18. Chen MJ, Liu JY, Li FQ, Chen HP, Liu YP: Screening of effective parts of Bletilla striata inhibiting tyrosinase and scavenging DPPH free radical and its preparation technology. J. Chengdu Univ. Tradit. Chin. Med. 2017; 40(2):15-9.

19. Huang H, Peng L, Liu L, Xiao DA: Inhibition effect of Hyaeinth Bletilla extract on activity of tyrosinase. China Sur Det Cos. 2008; 38(6):374-377.

20. Lu XF: Study of rhizoma Bletillae striatae extracts in inducing apoptosis on mice melanoma B16 cells. Chin Arch Tradit Chin Med. 2013; 31(7):1619-21.

21. Linghu L, Li CL, Yao XD: Effect of the aqueous extract of Bletilla striata on proliferation and migration of mouse melanoma B16F10 cells. J Zunyi Med Univ. 2018; 41(4):408-12.

22. Pillaiyar T, Manickam M, Namasivayam V: Skin whitening agents: medicinal chemistry perspective of tyrosinase inhibitors. J Enzyme Inhib Med Chem. 2017; 32(1):403-25.

23. Jiang F, Li W, Huang Y, Chen Y, Jin B, Chen N, Ding Z, Ding X: Antioxidant, antityrosinase and antitumor activity comparison: the potential utilization of fibrous root part of Bletilla striata (Thunb.) Reichb.f. PLoS One. 2013; 8(2):e58004.

24. Yu HS, Dai BL, Qian CD, Ding ZS, Jiang FS, Jin B, Li MY: Antibacterial activity of chemical constituents isolated from fibrous roots of Bletilla striata. Chin Med Mat. 2016; 39(3):544-7.

25. Bouhajeb R, Selmi S, Nakbi A, Jlassi I, Montevecchi G, Flamini G, Zarrad I, Dabbou S: Chemical composition analysis, antioxidant, and antibacterial activities of eggplant leaves. Chem Biodivers. 2020; 17(12):e2000405. 
26. Choi TY, Kim JH, Ko DH, Kim CH, Hwang JS, Ahn S, Kim SY, Kim CD, Lee JH, Yoon TJ: Zebrafish as a new model for phenotype-based screening of melanogenic regulatory compounds. Pigment Cell Res. 2007; 20(2):120-7.

27. Shi YP, Zhang YG, Li HN, Kong HT, Zhang SS, Zhang XM, Li XB, Liu KC, Han LW, Tian QP: Discovery and identification of antithrombotic chemical markers in Gardenia Fructus by herbal metabolomics and zebrafish model. J Ethnopharmacol. 2020; 253:112679.

28. Veselinovic JB, Veselinovic AM, Ilic-Tomic T, Davis R, O'Connor K, Pavic A, Nikodinovic-Runic J: Potent anti-melanogenic activity and favorable toxicity profile of selected 4-phenylhydroxycoumarins in the zebrafish model and the computational molecular modeling studies. Bioorg Med Chem. 2017; 25(24):6286-96.

29. Chen ZY, Chen SH, Chen CH, Chou PY, Yang CC, Lin FH: Polysaccharide extracted from Bletilla striata promotes proliferation and migration of human tenocytes. Polymers (Basel). 2020; 12(11):2567.

30. Ali JS, Saleem H, Mannan A, Zengin G, Mahomoodally MF, Locatelli M, Abidin S, Ahemad N, Zia M: Metabolic fingerprinting, antioxidant characterization, and enzyme-inhibitory response of Monotheca buxifolia (Falc.) A. DC. extracts. BMC Complement Med Ther. 2020; 20(1):313.

31. Kosakowska O, Baczek K, Przybyl JL, Pioro-Jabrucka E, Czupa W, Synowiec A, Gniewosz M, Costa R, Mondello L, Weglarz Z: Antioxidant and antibacterial activity of roseroot (Rhodiola rosea L.) dry extracts. Molecules. 2018; 23(7):1767.

32. Pandey BP, Pradhan SP, Adhikari K, Nepal S: Bergenia pacumbis from Nepal, an astonishing enzymes inhibitor. BMC Complement Med Ther. 2020; 20(1):198.

33. Xia QD, Xun Y, Lu JL, Lu YC, Yang YY, Zhou P, Hu J, Li C, Wang SG: Network pharmacology and molecular docking analyses on Lianhua Qingwen capsule indicate Akt1 is a potential target to treat and prevent COVID-19. Cell Prolif. 2020; 53(12):e12949.

34. Mahomoodally MF, Picot-Allain M, Zengin G, Llorent-Martinez EJ, Abdullah HH, Ak G, Senkardes I, Chiavaroli A, Menghini L, Recinella L et al: Phytochemical analysis, network pharmacology and in silico investigations on Anacamptis pyramidalis tuber extracts. Molecules. 2020; 25(10):2422.

35. Boo YC: Human skin lightening efficacy of resveratrol and its analogs: From in vitro studies to cosmetic applications. Antioxidants (Basel). 2019; 8(9):332.

36. Jung SH, Kim J, Eum J, Choe JW, Kim HH, Kee Y, Lee K: Velutin, an aglycone extracted from Korean mistletoe, with improved inhibitory activity against melanin biosynthesis. Molecules. 2019; 24(14):2549.

37. Kim DY, Won KJ, Hwang DI, Park SM, Kim B, Lee HM: Chemical composition, antioxidant and antimelanogenic activities of essential oils from Chrysanthemum boreale Makino at different harvesting stages. Chem Biodivers. 2018; 15(2):e1700506.

38. Kagotani K, Nakayama H, Zang L, Fujimoto Y, Hayashi A, Sono R, Nishimura N, Shimada Y: Lecithinbased dermal drug delivery for anti-pigmentation maize ceramide. Molecules. 2020; 25(7):1595.

39. Ullah S, Park C, Ikram M, Kang D, Lee S, Yang J, Park Y, Yoon S, Chun P, Moon HR: Tyrosinase inhibition and anti-melanin generation effect of cinnamamide analogues. Bioorg Chem. 2019; 87:43-55. 
40. Li L, Hao B, Zhang Y, Ji S, Chou G: Metabolite profiling and distribution of militarine in rats using UPLCQ-TOF-MS/MS. Molecules. 2020; 25(5):1082.

41. Kim MK, Bang CY, Kim MY, Lee JH, Ro H, Choi MS, Kim DI, Jang YP, Choung SY: Traditional herbal prescription LASAP-C inhibits melanin synthesis in B16F10 melanoma cells and zebrafish. BMC Complement Altern Med. 2016; 16:223.

42. Jeon HJ, Kim K, Kim C, Kim MJ, Kim TO, Lee SE: Molecular mechanisms of anti-melanogenic gedunin derived from neem tree (Azadirachta indica) using B16F10 mouse melanoma cells and early-stage zebrafish. Plants (Basel). 2021; 10(2):330.

43. Seo JO, Yumnam S, Jeong KW, Kim SY: Finasteride inhibits melanogenesis through regulation of the adenylate cyclase in melanocytes and melanoma cells. Arch Pharm Res. 2018; 41(3):324-32.

44. Mattio LM, Catinella G, Dallavalle S, Pinto A: Stilbenoids: A natural arsenal against bacterial pathogens. Antibiotics (Basel). 2020; 9(6):336.

\section{Figures}




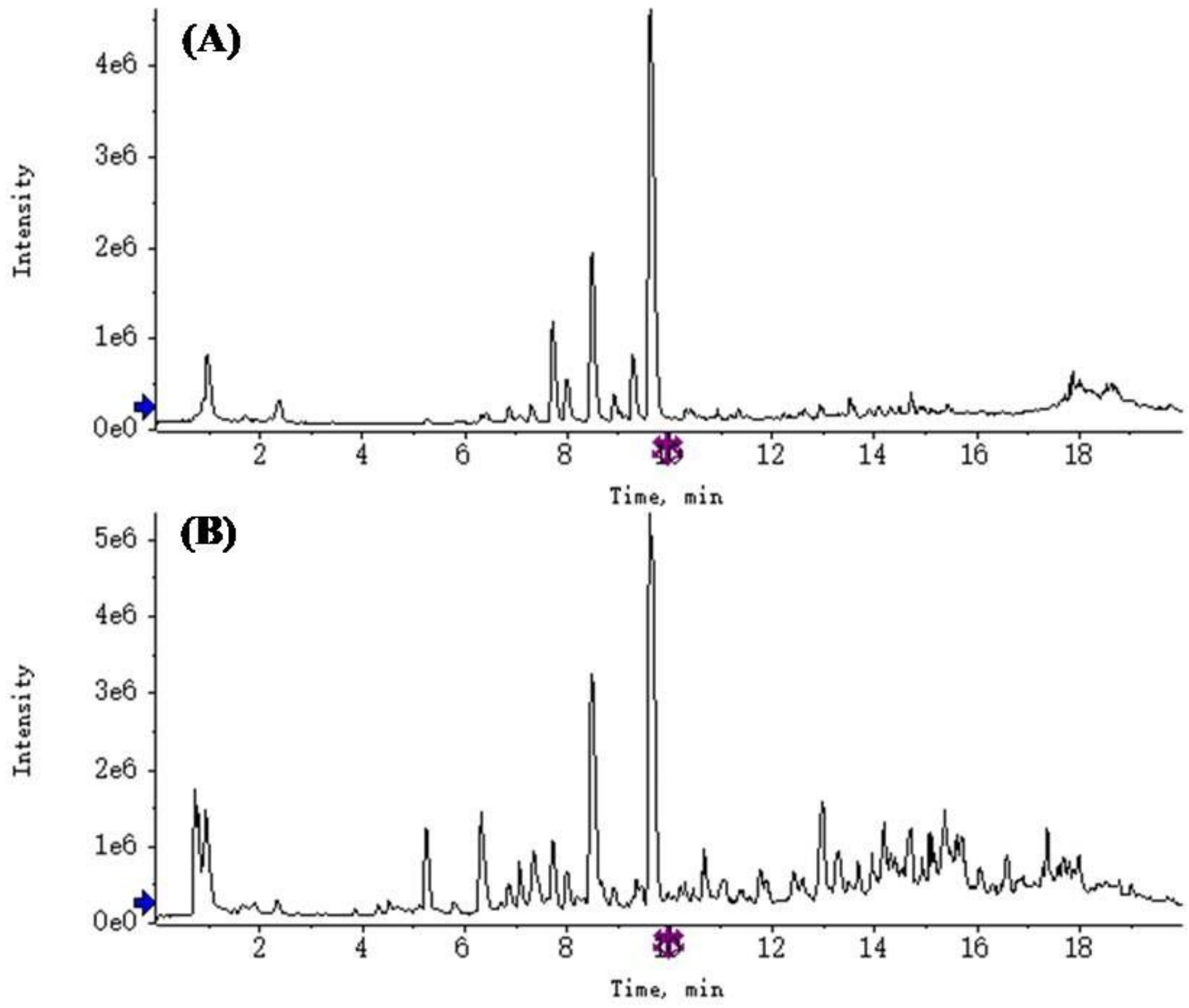

Figure 1

Base peak chromatogram of $95 \%$ ethanol extracts from B. striata tubers (A) and fibrous roots (B). 



Figure 2

Impact of melanogenic inhibitors on relative tyrosinase activity $(A)$ in vitro and melanin synthesis (B) in zebrafish embryos.


PTB, $10 \mathrm{mg} / \mathrm{L}$



ETB, $10 \mathrm{mg} / \mathrm{L}$



$0.05 \%$ DMSO

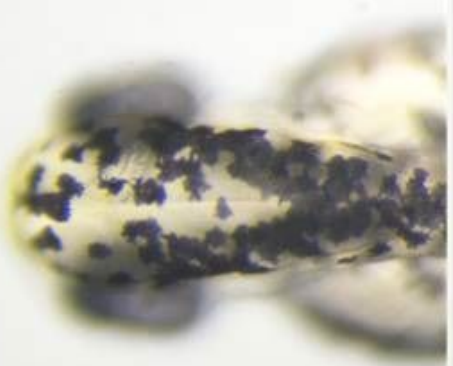

PTB, $30 \mathrm{mg} / \mathrm{L}$



ETB, $30 \mathrm{mg} / \mathrm{L}$

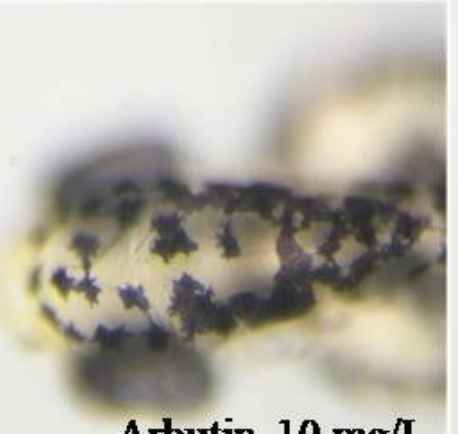

Arbutin, $10 \mathrm{mg} / \mathrm{L}$


EFB, $10 \mathrm{mg} / \mathrm{L}$

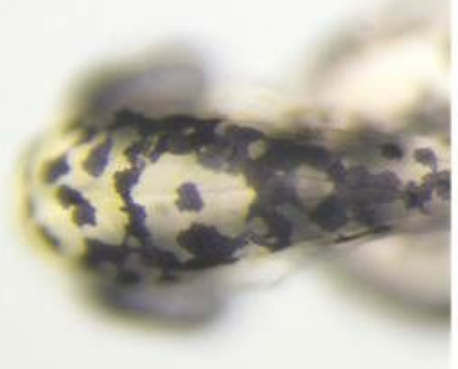

PFB, 30 mg/L

Arbutin, $30 \mathrm{mg} / \mathrm{L}$
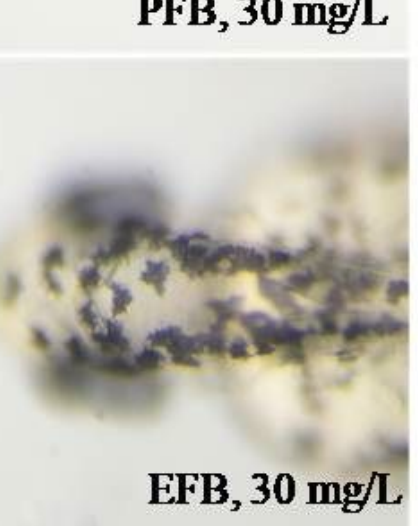

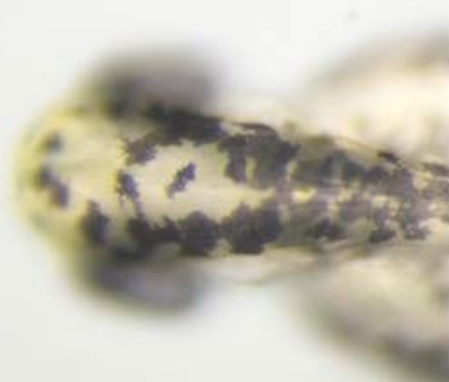




\section{Figure 3}

The impacts of PTB, PFB, ETB and EFB on the melanin synthesis of zebrafish embryos.


Figure 4

Best calculated poses for blestrin $D$ inside binding pocket of homology model of tyrosinase (A) and adenylate cyclase (B). 

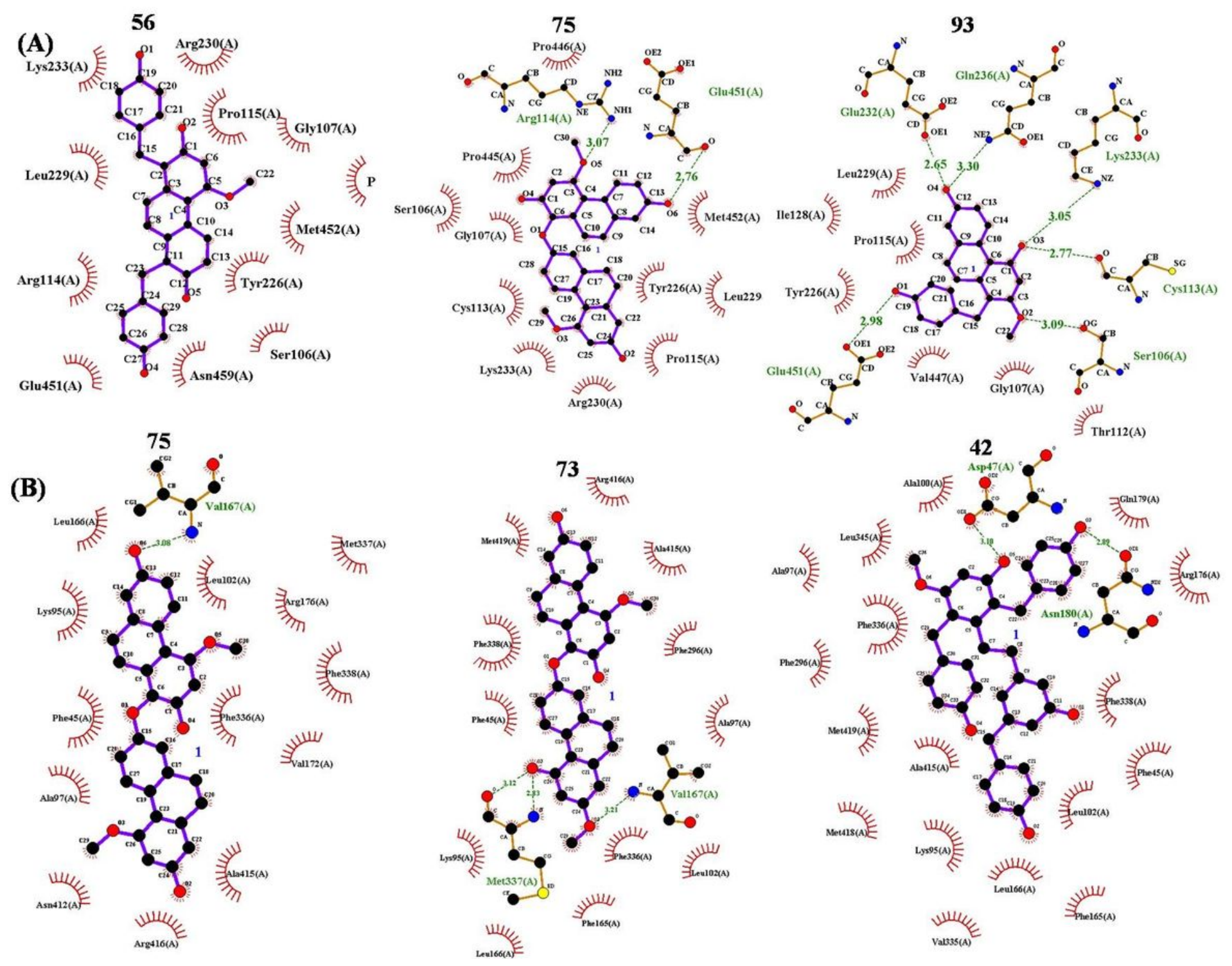

\section{Figure 5}

Two-dimensional representation of interaction between studied ligands and amino acids inside binding pocket of homology model of $(A)$ tyrosinase and $(B)$ adenylate cyclase.

\section{Supplementary Files}

This is a list of supplementary files associated with this preprint. Click to download.

- TableS120210819.pdf 